\title{
Effectiveness of a long-term Tecar Therapy treatment on Knee Pain: building T.T.E.S.S.K., an evaluating scale A systematic review and meta- analysis
}

Marco Sorrentino ( $\square$ marco.sorre.9756@gmail.com )

Università Vita-Salute San Raffaele Facoltà di Medicina e Chirurgia: Universita Vita-Salute San Raffaele Facolta di Medicina e Chirurgia https://orcid.org/0000-0001-6049-096X

\section{Davide Ferrari}

Università Cattolica del Sacro Cuore: Universita Cattolica del Sacro Cuore

\section{Zais Ilaria Elena}

Università degli Studi di Milano "LA STATALE" - Medical Department

\section{Research Article}

Keywords:

Posted Date: January 7th, 2022

DOI: https://doi.org/10.21203/rs.3.rs-1208847/v1

License: (c) (1) This work is licensed under a Creative Commons Attribution 4.0 International License.

Read Full License 


\section{Effectiveness of a long-term Tecar Therapy treatment on Knee Pain: building T.T.E.S.S.K., an evaluating scale A systematic review and meta-analysis}

Dr. Sorrentino Marco, from "Università degli Studi di Milano” (MI) Italy - Sport Science Department

Dr. Ferrari Davide, from "Università Cattolica del Sacro Cuore" (MI) Italy - Ostheopaty Department

Dr. Zais Ilaria, from "Università degli Studi di Milano" (MI), Italy - Medical Department

Background. T.E.C.a.R (Transfer of Energy Capacitive and Resistive) Therapy (TT) is a form of endogenous thermotherapy based on radio waves ${ }^{1}$. It is a non-invasive procedure, that makes use of a machine able to stimulate heat inside the body to repair the inflammatory processes. Although being well known in the physiotherapy and massage therapy ambient for its benefic effects, which are still not very explored especially physiological and biochemical ones; TT is commonly used by therapists for musculoskeletal diseases. Anyhow, TT is often used as a palliative remedy for musculoskeletal disease, or linked with an ibuprofen or antidolorific medical therapy, and not as a main cure. Current literature still lacks objective ways to evaluate TT treatment. This study aims to create an evaluating Scale for the knee joint lesions treated with TT, for athletes or sports enthusiasts.

Methods. PubMed, Embase, and Cochrane Library databases were screened to perform an extensive review. PRISMA guidelines were applied, and the risk of bias was assessed, as was the methodological quality of the included studies. 25 articles were reviewed. 178 patients (total amount of clinic cases in PubMed, Embase and Cochrane Library articles combined) have decreased their pain after a long-term TT treatment (> 3 or 5 sessions).

Results. Knee joint is often affected by non-sportive or sportive musculoskeletal lesions. ((At this point, not only the TT articles were reviewed, but also all the articles (122) that included these key aspects)). Six items were selected to evaluate the efficacy of TT on the impaired joint: Range of Motion (ROM), \%MVIC of quadriceps, biceps femoris and gastrocnemius, Cincinnati Rating Scale System (CRSS), NRS Pain Scale, Muscle Fiber Orientation (MFO) and \% Trigger Points.

Conclusions. Our study allows to build a new treatment methodology with TT. It guarantees the therapist to structure a long-lasting follow-up, which is not limited to the simple use of the machine. Applying this methodology, the patient receives a treatment that is not limited, but built on his own needs thanks to the distribution of the summing scores, strictly dependent on the type of clinical case that the therapist finds. Thanks to the six items we inserted in T.T.E.S.S.K. ("Tecar Therapy Evaluation Score System of the Knee"), every aspect of a musculotendinous pathology is recognized, and might be treated with TT by therapists.

\section{INTRODUCTION}

\section{Personal Preface}

Tecar therapy is considered and used for its benefits, which are many, especially considering how often its treatment becomes a remedy for a specific musculotendinous pathology. Physiotherapists, massage therapists and TT technicians use this therapeutic modality with the unique purpose of palliation, without however considering the biochemical and physiological aspects, which to date are still unexplored in the medicalscientific community. It is therefore difficult to determine the beneficial effects of the Tecar, but it is not possible to leave the placement of its treatment to chance. Therapists often use this method without knowledge of the facts, simply selecting a period in which using it, according to the severity of the pathology ${ }^{2}$ they encounter (or according to the patient request of use, due to a previous session). The purpose of this study, therefore, is to place the TT treatment in its own location that can be helpful not only for therapists who use it, but also to all medicalscientific departments that do not use it; despite this, it is important to state that it is not intention of this study providing a physiological description of the use of TT, but rather to demonstrate the benefits of its use. To support this thesis, our article aims to build a valuable scientific rating Scale, with which every therapist, who is adopting TT treatment, can find himself to better follow improvements or worsening of his clinical cases. Before talking about the construction of the evaluation Scale, it is necessary to make an important premise: this article is aimed to all therapists who have already decided to undertake a long-term TT treatment (> 5 sessions), and thanks to the Scale it is possible for them to follow step by step the progress of their patients ${ }^{3}$.

What is Tecar Therapy, its treatments and which are its effects?

Tecar therapy (TT) is an endogenous thermotherapy used to generate the heating of superficial and deep tissues ${ }^{4}$. An endogenous therapy is defined as a treatment which is not localized on the outermost layer of the dermis, but rather on the underlying layers. Precisely because of this property, TT is able to positively influence blood flow, promoting the elimination of catabolites and increasing specific peripheral vasodilation. The Tecar (capacitive and resistive energetic transfer) is an endogenous thermotherapy that uses electrical currents, induced by a $448 \mathrm{kHz}$ capacitive/resistive monopolar radiofrequency, to generate warming up of deep tissues. The Tecar device provides two different treatment modes: capacitive (CAP) and resistive (RES). These modes are normally delivered with different probes (electrodes), made of medical stainless steel. According to Tecar's developers, the two treatment modes induce different tissue responses depending on the resistance of 
the treated tissue. When the active electrode is provided with an insulating ceramic layer, acting as a dielectric medium, (CAP) the energetic transmission generates only heat in superficial tissue layers, with a selective action on low-impedance (water rich) soft tissues, for example, adipose tissue, muscle, cartilage, and lymphatic system. If the active electrode has no insulating layer, (RES) the radiofrequency energy passes directly through the body in the direction of the inactive electrode, generating heat in the deeper more resistant (low water content) tissue layers, for example, bone, muscular facia, capsules, and tendons.

\section{What is known in literature about Tecar Therapy?}

TT use in clinical practice has been relatively common for nearly 20 years, but only a few recent studies investigated its clinical efficacy ${ }^{5}$. Tecar Therapy treatment physiological effects are still non confirmed by any study. However, most of them reported encouraging results in decreasing pain and improving function in different musculoskeletal clinical conditions such as anterior knee pain. Despite some preliminary evidence on its clinical efficacy, there is a lack of knowledge on the physiological responses induced by TT and the known scientific literature is non-existent. This gap in the literature shows little interest in this complementary medicine, especially as regards its use in hospitals.

\section{How therapists use TT?}

Tecar is often used by therapists. It can be used by physiotherapists, massage therapists, orthopedics, and TT technicians. Thanks to its endogenous way of producing heat, the TT treatment is often used in sport therapy ${ }^{6}$, but also in simple muscular and tendinous pathologies. Most common sportive diseases: insertional tendinopathies of the Achilles, patellar pain or inflammation, wrist extensor tendons inflammation, knee pain, muscular instability, or pain. Its capability to affect the blood flow, because of its thermotherapeutic effect, is commonly considered one way in which TT supports the healing processes of injured/dysfunctional tissues. This ability is often considered its primary mechanism (in terms of physiotherapy, massage therapy and sports rehabilitation therapy) to promote healing processes. Some studies tried to include the TT treatment in a specific hospital programme, but they all failed, however one article suggested its use in Osteoarthritis (OA) knee joint disease, with great results. The main objective of the study was to compare the effects of deep versus superficial heating on pain and function in patients affected by moderate knee OA. DHT delivered through microwave diathermy produced a significant therapeutic effect in all outcomes considered. Improvements elicited by DHT were maintained over 12 months of follow-up. Despite this case, we cannot use this study to promote the TT use in all OA patients.

\section{"KNEE JOINT ROM"}

\section{Personal Preface}

Joint ROM is the first value that enters this evaluation Scale of a TT treatment. KJ-ROM is very important, because it is the first sign of a possible muscle or joint injury on which you can intervene with TT. For this reason, physiological and non-physiological values of KJROM will be listed in the next chapter during active and passive mobilization. For therapists it will be essential to evaluate any dysmorphism or paramorphism, not only for the joint but regarding the correct alignment of the body in space. In fact, it cannot be ruled out that knee injuries can be caused by incorrect body weight unloading. We chose knee joint because is one of the most affected joints by disease, pain, or sportive injuries. In fact, many diseases and injuries can impair joint mobility ${ }^{7}$.

\section{Why is Knee Joint ROM (KJ-ROM) important for TT treatment?}

Therapists must know when and where is possible to keep going with their TT treatment, especially when there are no progresses in pain or benefits in their clinic cases. For this reason, first step of construction for the evaluating Scale was to confront physiological aspects of musculoskeletal system with non-physiological ones. Normal reference values are needed to determine extent of impairment to assess and monitor joint motion. There is very little published data describing normal joint range of motion (ROM) for healthy men and women across a wide span of ages ${ }^{8}$. Health care providers, including physicians and therapists, provide interventions designed to restore joint mobility to reduce activity limitations. The severity of impaired joint mobility must be determined in comparison with normal reference values. It Is important to include KJ-ROM in the evaluating TT Scale, so therapists can decide in what direction the treatment is going and what should be next processes. TT clinicians should ask themselves: "Are there any benefits in the knee liberty degrees?"; "Is the treatment guaranteeing less problem during flexion and extension movements?"; "Is the knee swelling caused by an inflammation process going to affect the KJ-ROM?".

\section{How can therapists valuate KJ physiological ROM?}

A common method of joint mobility assessment is the measurement of joint range of motion (ROM) using a universal goniometer ${ }^{8}$. By aligning the stationary and movable arms of the device with specific bony landmarks on either side of the joint, the full extent of joint mobility can be measured in degrees. The most used reference values for joint ROM are those published by the American Academy of Orthopaedic Surgeons (AAOS). According to this study we can collocate numbers and results of goniometers in the table. Of course, it is important to consider differences between sex genres, laterality, age, and type of knee joint disease. 


\section{Physiological KJ-ROM goniometer results}

Female subjects have greater joint mobility in all age groups in nearly all joints and the gender difference was most obvious in measures of ankle plantarflexion, elbow pronation and supination. Range of motion average values for all joints decreased with advancing age for both men and women and, in most cases, were significantly different than most used normative values. Changes in joint ROM observed with puberty and ageing appear to be caused by changes in both joint laxity and body mass. While increased BMI decreases joint mobility overall, in female clinic cases joint ROM increases with onset of puberty despite physiological increases in BMI: all these body modifications during growing process are important to be taken into consideration. There were statistically significant differences between left and right sides in the measures of knee extension and flexion. These differences do not affect the construction of the Scale, because every therapist must know where to collocate his patient. For this reason, it is advisable to carry out a previous medical history into the treatment period, especially before valuating the clinical disease situation. In the anamnesis, it is important to define genre, age, laterality, previous diseases and musculoskeletal problems

\begin{tabular}{|l|l|}
\hline Female Knee flexion & Female Knee extension: \\
$2-8$ yrs old: 152.6 & $2-8$ yrs old: $5.4(3.9-$ \\
$(151.2-154.0)$ & $6.9)$ \\
$9-19$ yrs old: 142.3 & $9-19$ yrs old: $2.4(1.5-$ \\
$(140.8-143.8)$ & $3.3)$ \\
$20-44$ yrs old: 141.9 & $20-44$ yrs old: $1.6(1.1-$ \\
$(140.9-142.9)$ & $2.1)$ \\
$45-69$ yrs old: 137.8 & $45-69$ yrs old: $1.2(0.7-$ \\
$(136.5-139.1)$ & $1.7)$ \\
\hline Male Knee flexion & Male Knee extension \\
$2-8$ yrs. old: 147.8 & $2-8$ yrs old: $1.6(0.9-$ \\
$(146.6-149.0)$ & $2.3)$ \\
$9-19$ yrs. old: 142.2 & $9-19$ yrs old: $1.8(0.9-$ \\
$(140.4-144.0)$ & $2.7)$ \\
$20-44$ yrs. old: 137.7 & $20-44$ yrs old: $1.0(0.6-$ \\
$(136.5-138.9)$ & $1.4)$ \\
$45-69$ yrs old: 132.9 & $45-69$ yrs old: $0.5(0.1-$ \\
$(131.6-134.2)$ & $0.9)$ \\
\hline
\end{tabular}

\section{What can affect KJ physiological ROM?}

There are several specific diseases that can cause a decrease in KJ-ROM. Active ROM may be decreased because of pain or muscular weakness ${ }^{10}$. Therefore, passive ROM better estimates actual joint motion. For this reason, it is best to evaluate the KJ-ROM with a passive mobilization, and in important malalignment cases, with a medical supervision. In addition to passive mobilization, is very important defining the passive ROM with a titanium goniometer, where possible. But there are also other options. In a recent study, the mean coefficient of determination among the examiners demonstrated that $89 \%$ of the knee angles measured using the goniometer were explained by the variable analyzed using the smartphone application. This analysis is important, as it determines the percentage by which the model can explain the values encountered and demonstrates that the smartphone application is as reliable as a goniometer despite the nonuse of anatomic reference points, as required with the use of a goniometer. Thus, clinicians may prefer this novel technology, especially those who are less experienced with joint angle measurements. This new technology can also be used by therapists who are not able to acquire a titanium goniometer, as is known as a very expensive tool.

\section{KJ-ROM in the Scale}

\begin{tabular}{|c|c|}
\hline Knee Joint Flexion & Knee Joint Extension \\
\hline $1-10^{\circ}: 0$ points & $0-0.1^{\circ}: 0$ points \\
\hline $11-30^{\circ}: 1$ point & $0.2-0.3^{\circ}: 1$ point \\
\hline $31-70^{\circ}: 2$ points & $0.4-0.7^{\circ}: 2$ points \\
\hline $71-100^{\circ}: 3$ points & $0.8-1.2^{\circ}: 3$ points \\
\hline $101-120^{\circ}: 4$ points & $\begin{array}{l}1.3-1.6^{\circ}: 4 \text { points } \quad \text { (or } \\
\text { physiologic: } 8 \text { points) }\end{array}$ \\
\hline $\begin{array}{l}121-130^{\circ}: \quad 5 \text { points } \\
\text { physiologic: } 8 \text { points) }\end{array}$ & $\begin{array}{l}1.7-2.0^{\circ}: \quad 5 \text { points } \quad \text { (or } \\
\text { physiologic: } 8 \text { points) }\end{array}$ \\
\hline $\begin{array}{l}131-145^{\circ}: \quad 6 \text { points } \\
\text { physiologic: } 8 \text { points) }\end{array}$ & $\begin{array}{l}2.1-3.0^{\circ}: \quad 6 \text { points } \quad \text { (or } \\
\text { physiologic: } 8 \text { points) }\end{array}$ \\
\hline $\begin{array}{l}146-160^{\circ} />160^{\circ}: 7 \text { points (or } \\
\text { physiologic: } 8 \text { points) }\end{array}$ & $\begin{array}{l}3.1-5.5^{\circ} />5.5^{\circ}: 7 \text { points (or } \\
\text { physiologic: } 8 \text { points) }\end{array}$ \\
\hline
\end{tabular}

\section{\% MAXIMUM VOLUNTARY ISOMETRIC CONTRACTION (MVIC)}

\section{Personal Preface}

The second value entering the rating scale is $\%$ of Maximum Voluntary Isometric Contraction (\%MVIC) ${ }^{11}$. It will be widely descripted and summarized for our topic in the next paragraphs, but it is important to state that this value is not so easy to collect for all therapists. What does this mean? There are several ways to collect results from a \%MVIC evaluation: Electromyography (EMG), electrodes and 100\%Maximal Rep (1RM). EMG values are clearly the most efficient and precise ones, but also the most expensive to collect and not so affordable, especially for therapists; same as electrodes, but the results are often misleading. One of the best ways to collect muscular maximum voluntary contraction is by using the 1RM method. This option consists of carrying out an exercise with maximum tolerable load. Although it's easy to request a maximum squat, for example, it's not so easy to carry that out for an un-trained subject. That is another reason why this article is strictly focused on trained athletes ${ }^{12}$. Even though we tried normalizing 1RM 
method, we decided to limit values to electromyographic ones, as they can give a more objective and stable order for each clinical case ${ }^{13}$.

\section{What is the \% MVIC?}

Maximum voluntary isometric contraction (MVIC) is a standardized method for measurement of muscle strength in patients. The aim of the measurement of MVIC is to understand possible muscular diseases or deficits. It is often used in clinic cases with neuromuscular disease.

\section{Why is important \%MVIC for TT treatment?}

Therapists need to know when it is necessary to progress with Tecar therapy treatment, especially in clinical cases affected by neuromuscular defects. As we stated before, TT is often used as a palliative remedy, but without concerning the real condition of the muscle strength before therapy. It is important to consider MVIC, because the effect of TT on profound tissue might also affect muscular coating.

\section{What is known literature about \%MVIC?}

Maximum voluntary isometric contraction (MVIC) was introduced several years ago as an outcome measure for ALS for natural history studies and clinical trials. Values obtained from MVIC testing are difficult to interpret at present as normative data are limited. In older populations, obtaining true maximum voluntary excitation appears more difficult than in young populations. Different studies tried to determine whether differences between maximum voluntary excitation obtained from voluntary isometric contractions (MVIC) versus sub-maximum voluntary dynamic contractions (sMVDC) are age-dependent ${ }^{14}$.

\section{What are methods for \%MVIC valuation?}

The most applied method of normalization is by expressing activation as a percentage of maximum voluntary excitation, obtained during a maximum voluntary contraction. This maximum voluntary contraction can be performed either isometrically (MVIC) or dynamically (MVDC), for example during a Bilateral Squat (BS). Even though physical limitations might make it difficult to obtain a 'true' maximum voluntary excitation ${ }^{15}$, one should strive to normalize to a value that is as close as possible to the true maximum. True maximum contraction must be collected with EMG (Electromyography). Some studies about MVICs recorded at a single joint angle, which is the most common approach to isometric normalization and is least time consuming and susceptible to effects of fatigue. As for ROM valuation, we must consider differences between subjects and clinical cases. Age, genre, laterality are the most important ones. For example, young women $\%$ MVIC of vastus lateralis $(50 \%$ during a forward $10 \mathrm{~cm}$ step) is significantly different from old women during the same movement; but it's also significantly different from young women during a forward $30 \mathrm{~cm}$ step (130\%MVIC).
These results are comparable as far as for rectus femoris, biceps femoris, vastus medialis, gastrocnemius.

\section{How can \% MVIC be collected?}

Maximal voluntary isometric contraction (MVIC) must be collected before the participant completed any squats. MVIC for the vastus lateralis, vastus medialis, rectus femoris, and biceps femoris must be collected in short sitting with the knees flexed to 90 degrees using a gait belt around the distal third of the shank during both isometric knee extension and knee flexion ${ }^{16} .90$ degrees must be used to normalize quadriceps and hamstring activation to maximal activity during peak knee flexion. MVIC for the lateral and medial gastrocnemius must be collected with the subject lying prone and 10 degrees of plantarflexion. Knee flexion and ankle plantarflexion can be measured using a goniometer. Best way to gain results for this topic, is to request an isometric contraction during some anaerobic exercise (\%1RM must be calculated before the strength test). We tried to analyze 4 exercises, to decide which one better fits in the Scale:

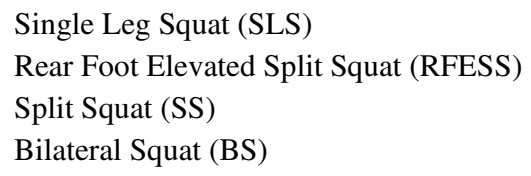

Each execution must be followed by a professional or personal trainer, who corrects certain incorrect positioning or incorrect weight discharges. For both SLS and SS it is essential to use a supra-lumbar belt, which helps better to unload charges, especially for those patients not used to exercising at high loads. BS is a commonly used exercise for strengthening quadriceps. Oftentimes, the exercise is not executed properly without initial instruction from a practitioner. Two common misalignments during a bodyweight bilateral squat are medial and anterior knee displacement, however there is little information about the changes in muscle activation patterns resulting from these malalignments ${ }^{17}$.

\section{Physiological \% MVIC of selected muscle}

- Vastus Lateralis (VL): it can be valuated with SLS, RFESS, SS and BS. VL had decreased activation during final ascent (96-99\% MVIC) of the squat cycle in the misaligned (ML) squat compared to the control squat. During BS exercise, VL reaches 100\%MVIC between 50 and $60 \%$ squat cycle and might reach its top between 60 $65 \%$ squat cycle, arriving at $110 \%$ MVIC.

- Vastus Medialis (VM): it can be valuated with SLS, RFESS, SS and BS. VM activation decreased during the final phase of ascent (92-98 \%MVIC) of the squat cycle in the ML misaligned squat compared to the control squat. During BS exercise, VM reaches 100\%MVIC between $50-55 \%$ squat cycle and might reach its top at $65 \%$ squat cycle, arriving at $120 \%$ MVIC.

- Rectus Femoris (RF): it can be valuated with SLS, RFESS, SS and BS. Rectus femoris activation decreased during the initial (15-18\%) and final phase of decent (28- 
$48 \%$ ) of the squat cycle in the ML misaligned squat compared to the control squat. The rectus femoris also displayed decreased activation in the ML misaligned squat during the final phase of ascent (85-99\%) of the squat cycle (11). During BS exercise, RF reaches $100 \%$ MVIC at $50 \%$ squat cycle, which is also its top contraction point.

- Biceps Femoris (BF): it can be valuated with SLS, RFESS and BS. The biceps femoris activation increased during the initial phase of descent (11-21\%) and beginning of the final phase of descent (25-28\%) during the ML misaligned squat compared to the control squat. During BS exercise, BF reaches 17\% MVIC between 50$55 \%$ squat cycle which is also its top contraction point.

Lateral Gastrocnemius (LG): it can be valuated with SLS and BS. The lateral head of the gastrocnemius was more active during the ML misaligned squat compared to the control squat in the initial (51-69\%) and final phase of ascent $(71-82 \%, 85-90 \%, 96-99 \%)$ during the squat cycle. During BS exercise, LG reaches 40\%MVIC between 75 $80 \%$ squat cycle which is also its top contraction point.

- Medial Gastrocnemius (MG): it can be valuated with SLS and BS. The medial head of the gastrocnemius was less active during the initial (1-7\%) and final phases of descent (29-32\%) of the ML misaligned squat compared to the control squat. During the ascending phases of the squat cycle, the medial gastrocnemius was more active in the ML misaligned squat $(65-69 \%, 75-78 \%, 85-94 \%)$ compared to the control squat. During BS exercise, MG reaches $30 \% \mathrm{MVIC}$ at $90 \%$ squat cycle, which is also its top contraction point.

We chose Bilateral Squat (BS) because it is the perfect compromise for patients (habituated performing squat or not) and therapists.

\section{\%MVIC in the Scale}

These values are EMG dependent, taken during a Bilateral Squat

\begin{tabular}{|c|c|c|c|c|c|c|}
\hline $\begin{array}{c}\text { VL } \\
\text { in } \\
\text { BS }\end{array}$ & $\mathbf{1 0 \%}$ & $\mathbf{2 0 \%}$ & $\mathbf{3 0 \%}$ & $\mathbf{4 0 \%}$ & $\mathbf{5 0 \%}$ & $\mathbf{6 0 \%}$ \\
\hline $1-$ & 8 & 5 & 4 & 3 & 2 & 1 \\
$11 \%$ & point & point & point & point & point & point \\
& $\mathrm{s}$ & $\mathrm{s}$ & $\mathrm{s}$ & $\mathrm{s}$ & $\mathrm{s}$ & \\
\hline $12-$ & 5 & 8 & 5 & 4 & 3 & 2 \\
$27 \%$ & point & point & point & point & point & point \\
& $\mathrm{s}$ & $\mathrm{s}$ & $\mathrm{s}$ & $\mathrm{s}$ & $\mathrm{s}$ & $\mathrm{s}$ \\
\hline $28-$ & 4 & 5 & 8 & 5 & 4 & 3 \\
$48 \%$ & point & point & point & point & point & point \\
& $\mathrm{s}$ & $\mathrm{s}$ & $\mathrm{s}$ & $\mathrm{s}$ & $\mathrm{s}$ & $\mathrm{s}$ \\
\hline $49-$ & 3 & 4 & 5 & 8 & 5 & 4 \\
$74 \%$ & point & point & point & point & point & point \\
& $\mathrm{s}$ & $\mathrm{s}$ & $\mathrm{s}$ & $\mathrm{s}$ & $\mathrm{s}$ & $\mathrm{s}$ \\
\hline $75-$ & 2 & 3 & 4 & 5 & 8 & 5 \\
105 & point & point & point & point & point & point \\
$\%$ & $\mathrm{~s}$ & $\mathrm{~s}$ & $\mathrm{~s}$ & $\mathrm{~s}$ & $\mathrm{~s}$ & $\mathrm{~s}$ \\
\hline
\end{tabular}

\begin{tabular}{|c|c|c|c|c|c|c|}
\hline $\begin{array}{c}105- \\
141\end{array}$ & 1 & 2 & 3 & 4 & 5 & 8 \\
$\%$ & point & point & point & point & point & point \\
s & & s & s & s & s \\
\hline
\end{tabular}

LG \%MVIC: $(\Delta \mathrm{n} \%=10 \%->(\Delta \mathrm{n}+1) \%=\Delta \mathrm{n} \%+5 \%) /$ BS \% cycle: $(\Delta \mathrm{n}=10 \%->(\Delta \mathrm{n}+1) \%=\Delta \mathrm{n} \%+10 \% \mathrm{U} \Delta \mathrm{n} \%<60 \%)$

\begin{tabular}{|c|c|c|c|c|c|c|}
\hline $\begin{array}{c}\text { VM } \\
\text { in } \\
\text { BS }\end{array}$ & $\mathbf{3 0 \%}$ & $\mathbf{3 5 \%}$ & $\mathbf{4 0 \%}$ & $\mathbf{4 5 \%}$ & $\mathbf{5 0 \%}$ & $\mathbf{5 5 \%}$ \\
\hline $1-$ & 8 & 5 & 4 & 3 & 2 & 1 \\
$11 \%$ & point & point & point & point & point & point \\
& s & s & s & s & s & \\
\hline $12-$ & 5 & 8 & 5 & 4 & 3 & 2 \\
$27 \%$ & point & point & point & point & point & point \\
& s & s & s & s & s & s \\
\hline $28-$ & 4 & 5 & 8 & 5 & 4 & 3 \\
$48 \%$ & point & point & point & point & point & point \\
& s & s & s & s & s & s \\
\hline $49-$ & 3 & 4 & 5 & 8 & 5 & 4 \\
$74 \%$ & point & point & point & point & point & point \\
& $\mathrm{s}$ & $\mathrm{s}$ & $\mathrm{s}$ & $\mathrm{s}$ & $\mathrm{s}$ & $\mathrm{s}$ \\
\hline $75-$ & 2 & 3 & 4 & 5 & 8 & 5 \\
105 & point & point & point & point & point & point \\
$\%$ & $\mathrm{~s}$ & $\mathrm{~s}$ & $\mathrm{~s}$ & $\mathrm{~s}$ & $\mathrm{~s}$ & $\mathrm{~s}$ \\
\hline $105-$ & 1 & 2 & 3 & 4 & 5 & 8 \\
141 & point & point & point & point & point & point \\
$\%$ & & $\mathrm{~s}$ & $\mathrm{~s}$ & $\mathrm{~s}$ & $\mathrm{~s}$ & $\mathrm{~s}$ \\
\hline
\end{tabular}

LG \%MVIC: $(\Delta \mathrm{n} \%=10 \%->(\Delta \mathrm{n}+1) \%=\Delta \mathrm{n} \%+5 \%) / \mathrm{BS} \%$

cycle: $(\Delta \mathrm{n}=30 \%->(\Delta \mathrm{n}+1) \%=\Delta \mathrm{n} \%+5 \%$ U $\Delta \mathrm{n} \%<55 \%)$

\begin{tabular}{|c|c|c|c|c|c|c|}
\hline $\begin{array}{c}\text { RF } \\
\text { in } \\
\text { BS }\end{array}$ & $\mathbf{0 \%}$ & $\mathbf{1 0 \%}$ & $\mathbf{2 0 \%}$ & $\mathbf{3 0 \%}$ & $\mathbf{4 0 \%}$ & $\mathbf{5 0 \%}$ \\
\hline $1-$ & 8 & 5 & 4 & 3 & 2 & 1 \\
$11 \%$ & point & point & point & point & point & point \\
& s & s & s & s & s & \\
\hline $12-$ & 5 & 8 & 5 & 4 & 3 & 2 \\
$27 \%$ & point & point & point & point & point & point \\
& s & s & s & s & s & s \\
\hline $28-$ & 4 & 5 & 8 & 5 & 4 & 3 \\
$48 \%$ & point & point & point & point & point & point \\
& s & s & s & s & s & s \\
\hline $49-$ & 3 & 4 & 5 & 8 & 5 & 4 \\
$74 \%$ & point & point & point & point & point & point \\
& $\mathrm{s}$ & $\mathrm{s}$ & $\mathrm{s}$ & $\mathrm{s}$ & $\mathrm{s}$ & $\mathrm{s}$ \\
\hline $75-$ & 2 & 3 & 4 & 5 & 8 & 5 \\
105 & point & point & point & point & point & point \\
$\%$ & $\mathrm{~s}$ & $\mathrm{~s}$ & $\mathrm{~s}$ & $\mathrm{~s}$ & $\mathrm{~s}$ & $\mathrm{~s}$ \\
\hline $105-$ & 1 & 2 & 3 & 4 & 5 & 8 \\
141 & point & point & point & point & point & point \\
$\%$ & & $\mathrm{~s}$ & $\mathrm{~s}$ & $\mathrm{~s}$ & $\mathrm{~s}$ & $\mathrm{~s}$ \\
\hline
\end{tabular}

LG \%MVIC: $(\Delta \mathrm{n} \%=10 \%->(\Delta \mathrm{n}+1) \%=\Delta \mathrm{n} \%+5 \%) / \mathrm{BS} \%$

cycle: $(\Delta \mathrm{n}=0 \%->(\Delta \mathrm{n}+1) \%=\Delta \mathrm{n} \%+10 \% \mathrm{U} \Delta \mathrm{n} \%<50 \%)$ 


\begin{tabular}{|c|c|c|c|c|c|c|}
\hline $\begin{array}{c}\text { BF } \\
\text { in } \\
\text { BS }\end{array}$ & $\mathbf{3 0 \%}$ & $\mathbf{3 5 \%}$ & $\mathbf{4 0 \%}$ & $\mathbf{4 5 \%}$ & $\mathbf{5 0 \%}$ & $\mathbf{5 5 \%}$ \\
\hline $1-$ & 8 & 5 & 4 & 3 & 2 & 1 \\
$3 \%$ & point & point & point & point & point & point \\
& $\mathrm{s}$ & $\mathrm{s}$ & $\mathrm{s}$ & $\mathrm{s}$ & $\mathrm{s}$ & \\
\hline $4-$ & 5 & 8 & 5 & 4 & 3 & 2 \\
$6 \%$ & point & point & point & point & point & point \\
& $\mathrm{s}$ & $\mathrm{s}$ & $\mathrm{s}$ & $\mathrm{s}$ & $\mathrm{s}$ & $\mathrm{s}$ \\
\hline $7-$ & 4 & 5 & 8 & 5 & 4 & 3 \\
$9 \%$ & point & point & point & point & point & point \\
& $\mathrm{s}$ & $\mathrm{s}$ & $\mathrm{s}$ & $\mathrm{s}$ & $\mathrm{s}$ & $\mathrm{s}$ \\
\hline $10-$ & 3 & 4 & 5 & 8 & 5 & 4 \\
12 & point & point & point & point & point & point \\
$\%$ & $\mathrm{~s}$ & $\mathrm{~s}$ & $\mathrm{~s}$ & $\mathrm{~s}$ & $\mathrm{~s}$ & $\mathrm{~s}$ \\
\hline $13-$ & 2 & 3 & 4 & 5 & 8 & 5 \\
15 & point & point & point & point & point & point \\
$\%$ & $\mathrm{~s}$ & $\mathrm{~s}$ & $\mathrm{~s}$ & $\mathrm{~s}$ & $\mathrm{~s}$ & $\mathrm{~s}$ \\
\hline $16-$ & 1 & 2 & 3 & 4 & 5 & 8 \\
18 & point & point & point & point & point & point \\
$\%$ & & $\mathrm{~s}$ & $\mathrm{~s}$ & $\mathrm{~s}$ & $\mathrm{~s}$ & $\mathrm{~s}$ \\
\hline
\end{tabular}

LG \%MVIC: $(\Delta \mathrm{n} \%=2 \%) /$ BS \% cycle: $(\Delta \mathrm{n}=30 \%$ -

$>(\Delta \mathrm{n}+1) \%=\Delta \mathrm{n} \%+5 \%$ U $\Delta \mathrm{n} \%<55 \%)$

\begin{tabular}{|c|c|c|c|c|c|c|}
\hline $\begin{array}{c}\text { LG } \\
\text { in } \\
\text { BS }\end{array}$ & $\mathbf{5 5 \%}$ & $\mathbf{6 0 \%}$ & $\mathbf{6 5 \%}$ & $\mathbf{7 0 \%}$ & $\mathbf{7 5 \%}$ & $\mathbf{8 0 \%}$ \\
\hline $1-$ & 8 & 5 & 4 & 3 & 2 & 1 \\
$7 \%$ & point & point & point & point & point & point \\
& s & s & s & s & s & \\
\hline $8-$ & 5 & 8 & 5 & 4 & 3 & 2 \\
15 & point & point & point & point & point & point \\
$\%$ & $\mathrm{~s}$ & $\mathrm{~s}$ & $\mathrm{~s}$ & $\mathrm{~s}$ & $\mathrm{~s}$ & $\mathrm{~s}$ \\
\hline $16-$ & 4 & 5 & 8 & 5 & 4 & 3 \\
24 & point & point & point & point & point & point \\
$\%$ & $\mathrm{~s}$ & $\mathrm{~s}$ & $\mathrm{~s}$ & $\mathrm{~s}$ & $\mathrm{~s}$ & $\mathrm{~s}$ \\
\hline $25-$ & 3 & 4 & 5 & 8 & 5 & 4 \\
34 & point & point & point & point & point & point \\
$\%$ & $\mathrm{~s}$ & $\mathrm{~s}$ & $\mathrm{~s}$ & $\mathrm{~s}$ & $\mathrm{~s}$ & $\mathrm{~s}$ \\
\hline $35-$ & 2 & 3 & 4 & 5 & 8 & 5 \\
45 & point & point & point & point & point & point \\
$\%$ & $\mathrm{~s}$ & $\mathrm{~s}$ & $\mathrm{~s}$ & $\mathrm{~s}$ & $\mathrm{~s}$ & $\mathrm{~s}$ \\
\hline $46-$ & 1 & 2 & 3 & 4 & 5 & 8 \\
57 & point & point & point & point & point & point \\
$\%$ & & $\mathrm{~s}$ & $\mathrm{~s}$ & $\mathrm{~s}$ & $\mathrm{~s}$ & $\mathrm{~s}$ \\
\hline
\end{tabular}

LG \%MVIC: $(\Delta \mathrm{n} \%=6 \%->(\Delta \mathrm{n}+1) \%=\Delta \mathrm{n} \%+1 \%) / \mathrm{BS} \%$

cycle: $(\Delta \mathrm{n}=55 \%->(\Delta \mathrm{n}+1) \%=\Delta \mathrm{n} \%+5 \%$ U $\Delta \mathrm{n} \%<80 \%)$

\begin{tabular}{|c|c|c|c|c|c|c|}
\hline $\begin{array}{c}\text { MG } \\
\text { in } \\
\text { BS }\end{array}$ & $\mathbf{4 0 \%}$ & $\mathbf{5 0 \%}$ & $\mathbf{6 0 \%}$ & $\mathbf{7 0 \%}$ & $\mathbf{8 0 \%}$ & $\mathbf{9 0 \%}$ \\
\hline $1-$ & 8 & 5 & 4 & 3 & 2 & 1 \\
$4 \%$ & point & point & point & point & point & point \\
& $\mathrm{s}$ & $\mathrm{s}$ & $\mathrm{s}$ & $\mathrm{s}$ & $\mathrm{s}$ & \\
\hline $5-$ & 5 & 8 & 5 & 4 & 3 & 2 \\
$9 \%$ & point & point & point & point & point & point \\
& $\mathrm{s}$ & $\mathrm{s}$ & $\mathrm{s}$ & $\mathrm{s}$ & $\mathrm{s}$ & $\mathrm{s}$ \\
\hline $10-$ & 4 & 5 & 8 & 5 & 4 & 3 \\
15 & point & point & point & point & point & point \\
$\%$ & $\mathrm{~s}$ & $\mathrm{~s}$ & $\mathrm{~s}$ & $\mathrm{~s}$ & $\mathrm{~s}$ & $\mathrm{~s}$ \\
\hline $16-$ & 3 & 4 & 5 & 8 & 5 & 4 \\
22 & point & point & point & point & point & point \\
$\%$ & $\mathrm{~s}$ & $\mathrm{~s}$ & $\mathrm{~s}$ & $\mathrm{~s}$ & $\mathrm{~s}$ & $\mathrm{~s}$ \\
\hline
\end{tabular}

\begin{tabular}{|c|c|c|c|c|c|c|}
\hline $22-$ & 2 & 3 & 4 & 5 & 8 & 5 \\
29 & point & point & point & point & point & point \\
$\%$ & s & s & s & s & s & s \\
\hline $30-$ & 1 & 2 & 3 & 4 & 5 & 8 \\
38 & point & point & point & point & point & point \\
$\%$ & & s & s & s & s & s \\
\hline
\end{tabular}

LG \%MVIC: $(\Delta \mathrm{n} \%=3 \%->(\Delta \mathrm{n}+1) \%=\Delta \mathrm{n} \%+1 \%) / \mathrm{BS} \%$

cycle: $(\Delta \mathrm{n}=40 \%->(\Delta \mathrm{n}+1) \%=\Delta \mathrm{n} \%+10 \%$ U $\Delta \mathrm{n} \%<90 \%)$

\section{CINCINNATI RATING SCALE SYSTEM (CRSS)}

\section{Personal Preface}

Third value that joins the rating Scale is the Cincinnati Rating Scale System (CRSS), also known as the Modified Cincinnati Score ${ }^{18}$. This value consists of a subjective medical history of the patient. It is one of the best validated scales present in the medical-scientific literature. CRSS is a specific questionnaire for knee deficits, for this reason it is best associated with this rating Scale. This questionnaire has been designed to give the therapist information as to how knee pain has affected ability to manage in everyday life. In addition to the patient's subjective response regarding knee pain, CRSS is divided into eight different sections, each of which determines more information regarding possible knee pathologies; every section has a different assigned score.

Which Sections are we going to consider?
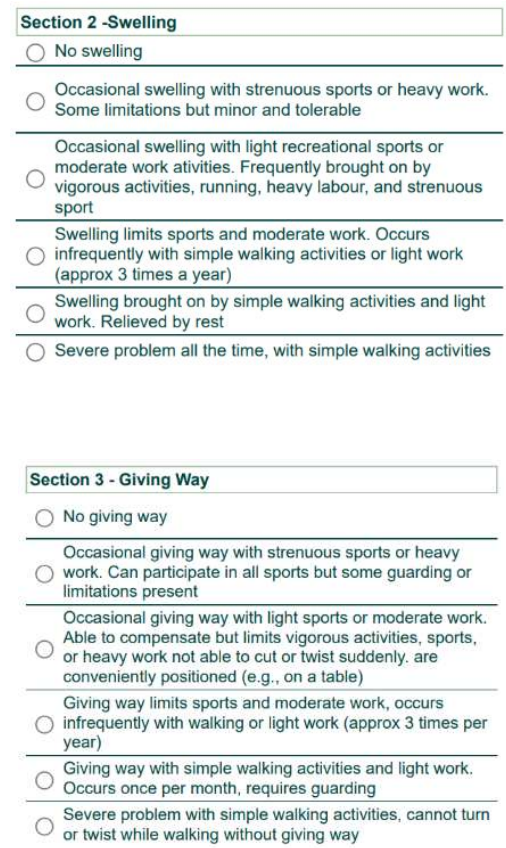

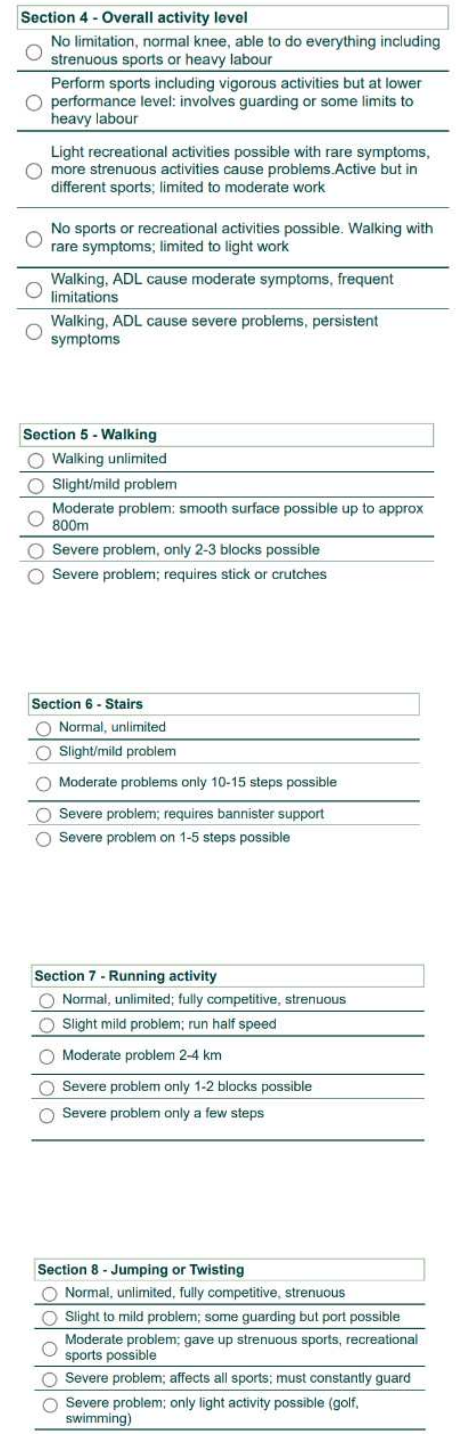

About Swelling and Inflammation ${ }^{19}$

The first stage of physiological or acute wound healing is dedicated to haemostasis and the formation of a provisional wound matrix, which occurs immediately after injury and is completed after some hours. For this reason, knee swelling is probably the most important section in CRSS questionnaire, because it might give clear information about continuing TT treatment. Tecar is a remedy recommended especially for the acute phase of inflammation, during which there is a strong vascular supply in the affected area. Sometimes this phase is also described as the 'lag-phase', in which the organism must manage the recruitment of the many cells and factors for the healing process in the absence of the mechanical strength of the wound. The inflammatory phase of the wound healing cascade gets activated during the haemostasis and coagulation phase and can roughly be divided into an early phase with neutrophil recruitment and a late phase with the appearance and transformation of monocytes. Work of the neutrophils is crucial within the first days after injury because their ability in phagocytosis and protease secretion kills local bacteria and helps to degrade necrotic tissue. Furthermore, they act as chemoattractants for other cells that are involved in the inflammatory phase. Apart from their actual support in wound healing, these molecules keep the healing process intact, as some of them can activate the next phase of wound healing (proliferative phase).

\section{CRSS confrontation with the Scale}

It is important to underline that the use of CRSS was not influenced by the inclusion in our evaluation scale. The simple reason is to keep the validated CRSS scale intact, and subsequently add its score with the other values present. As we will see later, CRSS is the only subjective value together with the NRS scale. All the others are based on physiological factors that cannot be influenced by the therapist who manages the treatment, but more influenced by the type of disease $^{20}$.

\section{NRS SCALE AND KNEE PAIN}

\section{Personal Preface}

Choosing the correct Pain scale is not easy ${ }^{21}$. There are different pain assessment scales, many of which are useful to define a value that respects the patient's subjectivity. Three scales (VAS, VRS, NRS) were in dispute with each other, and the NRS rating scale was chosen among the three. All three pain-rating scales are valid, reliable, and appropriate for use in clinical practice, although the Visual Analogue Scale (VAS) has more practical difficulties than the Verbal Rating Scale (VRS) or the Numerical Rating Scale (NRS). Pain rating scales have a fundamental place in clinical practice. The evidence suggests that patients can use them to communicate their pain experience and their response to treatment. The interpretation of pain scores is not straightforward. The key to successful pain management hinges upon the ability of the patient to use the tools made available, and the careful interpretation of the scores by the health care professionals. Intensity is not the only factor important in the experience of pain; pain occurs within a context. For example, in cancer patients the sensory component of pain is less important than the evaluative-emotional aspect. However, in our type of treatment, pain is a very important factor that must be taken into high consideration. Pain intensity is influenced by the meaning of the pain to the patient and its expected duration.

\section{Why selecting NRS?}

For general purposes NRS has good sensitivity and generates data that can be analysed for audit purposes. Sensitivity of a pain rating scales is the ability of the scale to detect change. The more levels a tool has the 
more sensitive it will be. A small change in pain is noticeable using a VAS but the small number of categories in the VRS demand that a much larger change in pain is required before the change shows up on the scale. VAS and NRS are superior in this aspect because they have greater sensitivity towards change $^{22}$. For these different reasons, NRS have been selected to be inserted in the Scale.

\section{NRS in literature}

NRSs had better compliance in 15 of 19 studies reporting this and were the recommended tool in 11 studies based on higher compliance rates, better responsiveness and ease of use, and good applicability relative to VAS/VRS. The NRS-11/VNRS-11 was most frequently used (n $1 / 426)$. Failure rates with the NRS and VRS are lower than failure rates with the VAS. In a study of 56 chronic pain patients the failure rates of the NRS and VRS was $2 \%\left(\begin{array}{lll}1 / 4 & 1\end{array}\right)$ and 0 respectively ${ }^{23}$. NRS can be used with most children older than 8 years of age, and behavioural observation scales are required for those unable to provide a selfreport. For patients with cancer-related pain, the NRS is the most frequently used instrument to measure pain intensity.

\section{How NRS detect pain?}

For general purposes, the Numerical Rating Scale (NRS) has good sensitivity and generates data that can be statistically analysed for audit purposes. Patients who seek a sensitive pain rating scale would probably choose this one. The NRS is a 11-, 21- or 101-point scale where the end points are the extremes of no pain and pain as bad as it could be, or "worst pain". NRS can be graphically or verbally delivered. When presented graphically the numbers are often enclosed in boxes and the scale is referred to as an 11- or 21point box scale depending on the number of levels of discrimination offered to the patient. There is no published information about the distribution or error of data obtained using the NRS. However, the scale is interval level and can provide data for parametric analysis.

\section{NRS in the Evaluation Scale and its use in Knee Pain}

NRS is a commonly used tool necessitating the patient rate his pain on a scale from 0 to 10 (11 values), with 0 indicating no pain and 10 reflecting the worst possible pain. NRS, sometimes, can be described as a scale from 1 to 10 which does not give the patient a solution to indicate no pain at all. It can be used with children who are able to understand numbers. Although, we are going to consider NRS as a 0 to 10 , without modifications at all. Pain scores are interpreted as:

$$
\begin{aligned}
& \bullet 0=\text { no pain } \\
& \bullet 1-3=\text { mild pain }
\end{aligned}
$$

- 4-6 = moderate pain

- 7-10 = severe pain

Anterior knee pain is one of the most common knee problems in physically active individuals ${ }^{24}$. The reason for anterior knee pain has been suggested to be multifactorial with patella abnormalities or extensor mechanism disorder leading to patellar malalignment during flexion and extension of the knee joint. Some patients complain mostly of non-specific knee pain, while others report patellar instability problems. Patients present with a variety of symptoms and clinical findings, meaning that a thorough clinical examination is the key for optimal treatment. Weakness of the quadriceps muscle, especially during eccentric contractions, is usually present in most anterior knee pain patients. However, irrespective of whether pain or instability is the major problem, hypotrophy, and reduced activity of the vastus medialis are often found, which result in an imbalance between vastus medialis and vastus lateralis. This imbalance needs to be corrected before quadriceps exercises are started (during the valuation of \% MVIC and KJ-ROM). Non-operative rehabilitation protocol should be divided into different phases based on the patient's progress. Patients with anterior knee pain mostly complain of nonspecific knee pain localized peripatellar, often anteromedially and/or retropatellarly. The goal of the first phase is to recognize pain and swelling with NRS scale.

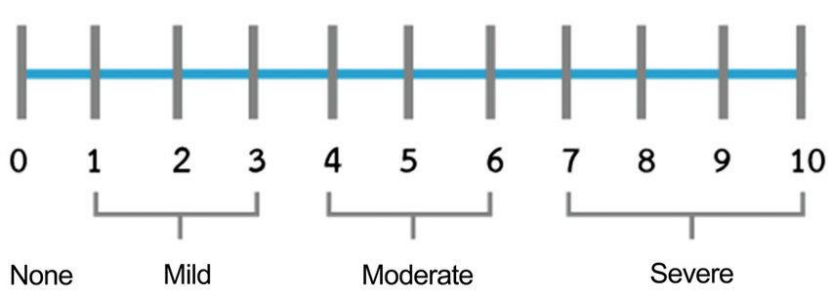

\section{NRS in the Scale}

We will use NRS system without affecting its facility of use and its structure. For this reason, NRS' score will be left intact:

$$
\begin{aligned}
& \text { 0: } 8 \text { points (physiological) } \\
& \text { 1-3: } 5 \text { points } \\
& \text { 4-6: } 3 \text { points } \\
& \text { 7-9: } 1 \text { point } \\
& \text { 10: } 0 \text { points }
\end{aligned}
$$

Recognizing Knee Pain causes with and without NRS Scale

There can be many causes of pain in the knee joint and all the accessory structures that make it up or that affect its movement or its physiological function. NRS can be a valuable aid in determining a precise location 
of pain, but it may often not be sufficient, and a less subjective examination by the therapist will be required. Passive mobilizations, isometric movements, maximal and submaximal muscle demands are just some of the main ones. It can be also useful improving the balance between vastus medialis and vastus lateralis, restore normal gait, and decrease loading of the patello-femoral joint. The second phase of treatment (after using NRS Scale) should include improvement on postural control and coordination of the lower extremity, increase of quadriceps strength and when needed hip muscle strength, and restore good knee function. Knee extensors are often weakened in patients with anterior knee pain. Isokinetic testing is the most optimal way for measuring muscle torques. Electromyography (EMG) recordings have been suggested to be important when evaluating the activity of the vasti muscles to diagnose anterior knee pain. Hypotrophy of the vastus medialis $(\mathrm{VM})$ is also common in anterior knee pain patients. Here some useful steps to recognize cause of knee pain. It is important to state that this article does not aim to help understand main causes of knee pain but wants to help therapist treat it with a long-term TT, localizing the treatment in a specific rehab protocol.

\section{MUSCLE FIBER ORIENTATION (MFO)}

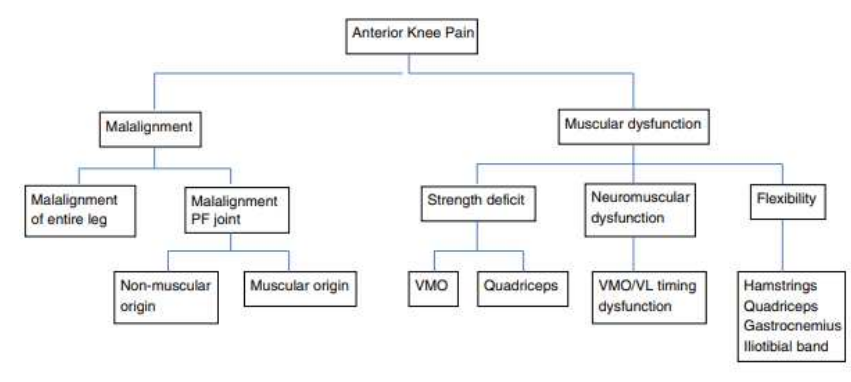

Personal Preface

Muscle Fiber Orientation (MFO) is largely used in common medical-scientific literature. Main reason for this use is to prevent eventual muscle disease or recognize muscle fiber malalignment. Why is alignment so important? It can be very useful to determine possible unloading charges, especially on the knee joint. Orthopaedics use MFO to describe common laterality problems or to include Muscle Fiber Orientation in a more complete patient musculoskeletal anamnesis. In this Scale we are going to include MFO malalignment and use it as a comparison between physiological MFO.

\section{What is MFO?}

Muscle fiber orientation (MFO) is an important value related to musculoskeletal functions, such as fiber architecture. MFO is commonly used in articles and reviews, it can give a great all-in-one valuation of the muscle non-physiological parameters. MFO represents length, orientation, and alignment of muscle fiber ${ }^{25}$.

How is MFO valuated?

The morphology of human thigh muscles is of great interest for clinicians, including pathologists and radiologists, and for sports medicine enthusiasts ${ }^{26}$. Automatic methods proposed in recent years also involved voting procedures which were computationally expensive. Ultrasonography is being widely used as a clinical and research tool for dynamic studies of the muscle during contraction and relaxation, since it is real-time, widely available, radiation-free, and low-cost. Muscle architectural characteristics, such as pennation angle or fiber orientation, fascicle length, fascicle curvature and muscle thickness, can be extracted from ultrasonography to evaluate the muscle function and activity. Changes of these architectural parameters over the time can form quantitative observations of muscle behaviour under contraction. Traditionally, fibers and their orientations in musculoskeletal sonograms were detected manually by drawing lines using NIH image software (National Institutes of Health, Bethesda, MD, USA ${ }^{27}$. This is currently one of the best ways to understand fiber orientation, especially considering its low budget request.

\section{MFO in the Scale}

Despite its use in clinical cases, and its facility of use, MFO will not be inside this evaluation Scale. The main reasons are its subjectivity; it is very difficult to compare this value to all the objective parameters we are including in the Scale. In fact, MFO hardly considers differences in genres, laterality, and specific clinic case. Nevertheless, MFO and fiber architecture can both be used to determine a malalignment in muscle fiber, and better define TT treatment, even though they remain therapist-choice related.

\section{MASSAGE THERAPY, MPS AND TRIGGER POINTS}

\section{Personal Preface}

The term myofascial pain syndrome (MPS) ${ }^{28}$, denoting pain coming from myofascial (muscle) Trigger Points (TrPs), was popularized by Travell and Simons ${ }^{29}$. They emphasized the concept of pain arising from specific small, hardened, tender regions in muscle identifiable by palpation. They called these hardened and tender spots trigger points. Their revolutionary concept was that pain caused by a trigger point can be manifested at a considerable distance from the $\operatorname{TrP}$ itself, which is termed referred pain, the principal mechanism by which myofascial $\operatorname{TrP}$ pain is 
manifested clinically. There is still controversy as to the relevance of TrPs. In the common scientific literature, myofascial pain is not considered as a medical-scientific approved pathology, in fact there is not an available and recognized therapy for this syndrome.

\section{Concerning MPS and TrPs}

Myofascial pain syndrome (MPS) is a common skeletal muscle disorder associated with regional muscle pain and tenderness, characterized by the presence of myofascial trigger points. TrPs are hyperirritable nodules along a taut band within a skeletal muscle and can be readily identified through palpation by trained therapists. MPS caused by trigger points in muscle are a common cause of local and generalized pain. Trigger points are hyperirritable zones in contracted bands of muscle, thought to be caused by muscle overload or stress. Myofascial pain may be unrecognized because the presenting symptoms are often headache, neck and shoulder pain, pelvic pain, limb pain, knee pain, or neural pain syndromes, although each specific pain syndrome may have a significant myofascial trigger point comorbidity. These different pain syndromes are related to the position of trigger itself.

\section{Recognizing and defining TrPs}

The TrP, focal pain generator in muscle, is a contracted band of muscle that is exquisitely tender to palpation. The $\operatorname{TrP}$ is a peripheral nociceptor, capable of inducing peripheral and central sensitization and referred pain. The easiest and most efficient way to diagnose myofascial pain syndrome caused by a $\operatorname{TrP}$ is by manual palpation of the muscle. Trigger points have an electromyographic signature termed SEA (spontaneous electrical activity) or endplate noise, which is persistent, fast, low-amplitude (950 UV or less) activity with less frequent, high-amplitude discharges of approximately $600 \mathrm{UV}^{30}$. Spontaneously painful TrPs are termed active, whereas TrPs that are tender only when palpated, but are not a cause of spontaneous pain, are termed latent. Nonpainful, latent, $\operatorname{TrPs}$ are not truly inactive, however. They have a host of abnormal effects, including disordered pattern of muscle recruitment.

\section{Treatment of $\operatorname{TrPs}$}

There are several ways to treat trigger points: some of them are endogenous and others are exogenous. Trigger point needling or injection ${ }^{31}$ can be effective in inactivating $\mathrm{TrP}$, but correcting triggers is also critical. Best way to treat MPS and especially TrPs zone, is with a massage therapy. An article tried to standardize massage treatment, for better understanding non-activation and activation of TrPs. A standardized 45-min massage protocol was followed at each session. Briefly, 15 mins of myofascial release applied to warm soft tissues of the upper back, shoulders, chest, and neck was conducted; 20 mins of trigger point release (TPR) applied bilaterally to TrPs in the upper trapezius, suboccipital muscles, and sternocleidomastoid; the final 10 mins consisted of post isometric relaxation directed at the right and left lateral cervical flexion, circular or cross-fiber friction on the masseter, temporalis, and occipitofrontalis muscles and ended with gentle effleurage and petrissage to the neck and shoulders. This protocol advisable for knee pain (or anterior knee pain) and TrPs located in quadriceps belly.

\section{Knee Joint TrPs}

Due to its articular construction, knee joint is one of the most affected joints by myofascial pain (MPS) and trigger points (TrPs). All three vastus can be affected, but also joint stabilizers such as biceps femoris and gastrocnemius. For its big belly, one of the most influenced by MPS is the rectus femoris. Trigger points in the vastus medialis refer pain to the medial aspect of the knee, whereas those in the vastus lateralis refer pain to the lateral zone of the knee; TrPs in the rectus femoris refer pain to the knee in general and can be delocalized up and down in the belly. For example, posttotal knee-replacement-restricted range of motion can be improved rapidly by inactivating TrPs in the quadriceps muscle. An elegant randomized, placebocontrolled trial clearly established that treatment of TrPs immediately before total knee replacement significantly shortened the time to achieving pain relief after surgery.

\section{How TrPs will be inserted in the Scale?}

We will consider TrPs in the Knee Joint as "myofascial lines". What does this mean? A TrP is not often considered as a single point, but it is near other ones or its pain creates a pain area. We can consider this gathering as a "TrPs Line". Score in the Scale will be determine considering how many Trigger Points there are in the line.

\begin{tabular}{|l|l|}
\hline TrPs Line: $10+$ & 0 points \\
\hline TrPs Line: $7-9$ & 1 point \\
\hline TrPs Line: $4-6$ & 3 points \\
\hline TrPs Line: $1-3$ & 5 points \\
\hline TrPs Line: 0 & 8 points \\
\hline
\end{tabular}

\section{"Tecar Therapy Evaluation Score System of the Knee"}

Building T.T.E.S.S.K.

\section{CRSS}

\section{Swelling}

\begin{tabular}{|l|l|l|}
\hline No Swelling & $\begin{array}{l}10 \\
\text { points }\end{array}$ & $\square$ \\
\hline $\begin{array}{l}\text { Occasional swelling with strenuous sports } \\
\text { or heavy work. Some limitations but } \\
\text { minor and tolerable }\end{array}$ & 8 points & $\square$ \\
\hline
\end{tabular}




\begin{tabular}{|l|l|l|}
\hline $\begin{array}{l}\text { Occasional swelling with light } \\
\text { recreational sports or moderate work } \\
\text { activities. Frequently brought on by } \\
\text { vigorous activities, running, heavy labour } \\
\text { and strenuous sport }\end{array}$ & 6 points & $\square$ \\
\hline $\begin{array}{l}\text { Swelling limits sports and moderate work. } \\
\text { Occurs infrequently with simple walking } \\
\text { activities or light work (approx. 3 times a } \\
\text { year) }\end{array}$ & 4 points & $\square$ \\
\hline $\begin{array}{l}\text { Swelling brought on by simple walking } \\
\text { activities and light work. Relieved by rest }\end{array}$ & 2 points & $\square$ \\
\hline $\begin{array}{l}\text { Severe problem all the time, with simple } \\
\text { walking activities }\end{array}$ & 0 points & $\square$ \\
\hline
\end{tabular}

\section{Giving Way}

\begin{tabular}{|l|l|l|}
\hline No giving way & $\begin{array}{l}20 \\
\text { points }\end{array}$ & $\square$ \\
\hline $\begin{array}{l}\text { Occasional giving way with strenuous } \\
\text { sports or heavy work. Can participate in } \\
\text { all sports but some guarding or limitations } \\
\text { present }\end{array}$ & $\begin{array}{l}16 \\
\text { points }\end{array}$ & $\square$ \\
\hline $\begin{array}{l}\text { Occasional giving way with light sports or } \\
\text { moderate work. Able to compensate but } \\
\text { limits vigorous activities, sports, or heavy } \\
\text { work not able to cut or twist suddenly, are } \\
\text { conveniently positioned }\end{array}$ & 12 & points \\
\hline $\begin{array}{l}\text { Giving way limits sports and moderate } \\
\text { work, occurs infrequently with walking or } \\
\text { light work (approx. 3 times per year) }\end{array}$ & 8 points & $\square$ \\
\hline $\begin{array}{l}\text { Giving way with simple walking activities } \\
\text { and light work. Occurs once per month, } \\
\text { requires guarding }\end{array}$ & 4 points & $\square$ \\
\hline $\begin{array}{l}\text { Severe problem with simple walking } \\
\text { activities, cannot turn or twist while } \\
\text { walking without giving way }\end{array}$ & 0 points & $\square$ \\
\hline
\end{tabular}

\section{Overall activity level}

\begin{tabular}{|l|l|l|}
\hline $\begin{array}{l}\text { No limitation, normal knee, able to do } \\
\text { everything including strenuous sports or } \\
\text { heavy labour }\end{array}$ & $\begin{array}{l}20 \\
\text { points }\end{array}$ & $\square$ \\
\hline $\begin{array}{l}\text { Perform sports including vigorous } \\
\text { activities but at a lower performance level } \\
\text { involves guarding or some limits to heavy } \\
\text { labour }\end{array}$ & $\begin{array}{l}16 \\
\text { points }\end{array}$ & $\square$ \\
\hline $\begin{array}{l}\text { Light recreational activities possible with } \\
\text { rare symptoms, more strenuous activities } \\
\text { cause problems. Active but in different } \\
\text { sports, limited to moderate work }\end{array}$ & 12 & points \\
\hline $\begin{array}{l}\text { No sports or recreational activities } \\
\text { possible. Walking with rare symptoms; } \\
\text { limited to light work }\end{array}$ & 8 points & $\square$ \\
\hline $\begin{array}{l}\text { Walking. ADL cause moderate symptoms, } \\
\text { frequent limitations }\end{array}$ & 4 points & $\square$ \\
\hline $\begin{array}{l}\text { Walking. ADL cause severe problems, } \\
\text { persistent symptoms }\end{array}$ & 0 points & $\square$ \\
\hline
\end{tabular}

\section{Walking}

\begin{tabular}{|l|l|l|}
\hline Walking unlimited & $\begin{array}{l}10 \\
\text { points }\end{array}$ & $\square$ \\
\hline Slight/mild problem & 8 points & $\square$ \\
\hline $\begin{array}{l}\text { Moderate problem: smooth surface } \\
\text { possible up to approx. } 800 \mathrm{~m}\end{array}$ & 6 points & $\square$ \\
\hline
\end{tabular}

\begin{tabular}{|l|l|l|}
\hline Severe problem, only 2-3 blocks possible & 4 points & $\square$ \\
\hline
\end{tabular}

\begin{tabular}{l|l|l}
\hline Severe problem, requires stick or crutches & 2 points & $\square$ \\
\hline
\end{tabular}

Stairs

\begin{tabular}{|l|l|l|}
\hline Normal, unlimited & $\begin{array}{l}12 \\
\text { points }\end{array}$ & $\square$ \\
\hline Slight/mild problem & $\begin{array}{l}10 \\
\text { points }\end{array}$ & $\square$ \\
\hline $\begin{array}{l}\text { Moderate problems only 10-15 steps } \\
\text { possible }\end{array}$ & 8 points & $\square$ \\
\hline $\begin{array}{l}\text { Severe problem, requires bannister } \\
\text { support }\end{array}$ & 6 points & $\square$ \\
\hline Severe problem on 1-5 step possible & 4 points & $\square$ \\
\hline
\end{tabular}

\section{Running activity}

\begin{tabular}{|l|l|l|}
\hline $\begin{array}{l}\text { Normal, unlimited: fully competitive, } \\
\text { strenuous }\end{array}$ & 5 points & $\square$ \\
\hline Slight mild problem, run half speed & 4 points & $\square$ \\
\hline Moderate problems 2-4 km & 3 points & $\square$ \\
\hline Severe problem only 1-2 blocks possible & 2 points & $\square$ \\
\hline Severe problem only few steps & 1 point & $\square$ \\
\hline
\end{tabular}

\section{KNEE ROM}

\begin{tabular}{|c|c|c|}
\hline $\begin{array}{l}\text { Knee Joint } \\
\text { Flexion }\end{array}$ & & \\
\hline $1-10^{\circ}:$ & 0 points & $\square$ \\
\hline $11-30^{\circ}:$ & 1 point & $\square$ \\
\hline $31-70^{\circ}:$ & 2 points & $\square$ \\
\hline $71-100^{\circ}:$ & 3 points & $\square$ \\
\hline 101-120': & 4 points & $\square$ \\
\hline 121-130': & $\begin{array}{c}5 \text { points (or physiologic: } 8 \\
\text { points) }\end{array}$ & $\square$ \\
\hline 131-145 : & $\begin{array}{c}6 \text { points (or physiologic: } 8 \\
\text { points) }\end{array}$ & $\square$ \\
\hline $146-160^{\circ} />160^{\circ}:$ & $\begin{array}{c}7 \text { points (or physiologic: } 8 \\
\text { points) }\end{array}$ & $\square$ \\
\hline \multicolumn{3}{|l|}{$\begin{array}{l}\text { Knee Joint } \\
\text { Extension }\end{array}$} \\
\hline $0-0.1^{\circ}:$ & 0 points & $\square$ \\
\hline $0.2-0.3^{\circ}:$ & 1 point & $\square$ \\
\hline $0.4-0.7^{\circ}:$ & 2 points & $\square$ \\
\hline $0.8-1.2^{\circ}:$ & 3 points & $\square$ \\
\hline 1.3-1.6 & 4 points & $\square$ \\
\hline $1.7-2.0^{\circ}:$ & $\begin{array}{c}5 \text { points (or physiologic: } 8 \\
\text { points) }\end{array}$ & $\square$ \\
\hline 2.1-3.0 $:$ & $\begin{array}{c}6 \text { points (or physiologic: } 8 \\
\text { points) }\end{array}$ & $\square$ \\
\hline $3.1-5.5^{\circ} />5.5^{\circ}:$ & $\begin{array}{c}7 \text { points (or physiologic: } 8 \\
\text { points) }\end{array}$ & $\square$ \\
\hline
\end{tabular}

\section{\%MVIC}

\% MVIC in Upper-Front Loggia

\begin{tabular}{|c|c|c|c|c|c|}
\hline $\begin{array}{c}\text { VL in } \\
\text { BS }\end{array}$ & $\mathbf{6 0 \%}$ & $\begin{array}{c}\text { VM in } \\
\text { BS }\end{array}$ & $\mathbf{5 5 \%}$ & $\begin{array}{c}\text { RF in } \\
\text { BS }\end{array}$ & $\mathbf{5 0 \%}$ \\
\hline $1-11 \%$ & 1 point & $1-11 \%$ & 1 point & $1-11 \%$ & 1 point \\
\hline
\end{tabular}




\begin{tabular}{|c|c|c|c|c|c|}
\hline $\begin{array}{c}12- \\
27 \%\end{array}$ & $\begin{array}{c}2 \\
\text { points }\end{array}$ & $\begin{array}{c}12- \\
27 \%\end{array}$ & $\begin{array}{c}2 \\
\text { points }\end{array}$ & $\begin{array}{c}12- \\
27 \%\end{array}$ & $\begin{array}{c}2 \\
\text { points }\end{array}$ \\
\hline $28-$ & 3 & $28-$ & 3 & $28-$ & 3 \\
$48 \%$ & points & $48 \%$ & points & $48 \%$ & points \\
\hline $49-$ & 4 & $49-$ & 4 & $49-$ & 4 \\
$74 \%$ & points & $74 \%$ & points & $74 \%$ & points \\
\hline $75-$ & 5 & $75-$ & 5 & $75-$ & 5 \\
$105 \%$ & points & $105 \%$ & points & $105 \%$ & points \\
\hline $105-$ & 8 & $105-$ & 8 & $105-$ & 8 \\
$141 \%$ & points & $141 \%$ & points & $141 \%$ & points \\
\hline
\end{tabular}

\%MVIC in Lower and Upper-Back Loggia

\begin{tabular}{|c|c|c|c|c|c|}
\hline $\begin{array}{c}\text { LG in } \\
\text { BS }\end{array}$ & $\mathbf{8 0 \%}$ & $\begin{array}{c}\text { MG } \\
\text { in BS }\end{array}$ & $\mathbf{9 0 \%}$ & $\begin{array}{c}\text { BF in } \\
\text { BS }\end{array}$ & $\mathbf{5 5 \%}$ \\
\hline $1-7 \%$ & 1 point & $1-4 \%$ & 1 point & $1-3 \%$ & 1 point \\
\hline $8-15 \%$ & 2 & $5-9 \%$ & $\begin{array}{c}2 \\
\text { points }\end{array}$ & $4-6 \%$ & $\begin{array}{c}2 \\
\text { points }\end{array}$ \\
\hline $16-$ & 3 & $10-$ & 3 & $7-9 \%$ & 3 \\
$24 \%$ & points & $15 \%$ & points & & points \\
\hline $25-$ & 4 & $16-$ & 4 & $10-$ & 4 \\
$34 \%$ & points & $22 \%$ & points & $12 \%$ & points \\
\hline $35-$ & 5 & $22-$ & 5 & $13-$ & 5 \\
$45 \%$ & points & $29 \%$ & points & $15 \%$ & points \\
\hline $46-$ & 8 & $30-$ & $\begin{array}{c}8 \\
\text { points }\end{array}$ & $\begin{array}{c}16- \\
18 \%\end{array}$ & $\begin{array}{c}8 \\
\text { points }\end{array}$ \\
\hline $57 \%$ & points & $38 \%$ & \multicolumn{4}{|c}{} \\
\hline \multicolumn{7}{|c|}{} & \multicolumn{4}{|c|}{} \\
\hline
\end{tabular}

\section{NRS SCALE}

\begin{tabular}{|l|l|l|}
\hline 0 (none) & 8 points & $\square$ \\
\hline $1-3$ (mild) & 5 points & $\square$ \\
\hline $4-6$ (moderate) & 3 points & $\square$ \\
\hline $7-9$ (severe) & 1 point & $\square$ \\
\hline 10 (top) & 0 points & $\square$ \\
\hline
\end{tabular}

\section{TRPS LINE}

\begin{tabular}{|l|l|l|}
\hline TrPs Line: $10+$ & $\begin{array}{l}0 \\
\text { points }\end{array}$ & $\square$ \\
\hline TrPs Line: $7-9$ & 1 & $\square$ \\
& point & \\
\hline TrPs Line: $4-6$ & 3 & $\square$ \\
& points & \\
\hline TrPs Line: $1-3$ & 5 & $\square$ \\
& points & \\
\hline TrPs Line: 0 & $\begin{array}{l}8 \\
\text { points }\end{array}$ & $\square$ \\
\hline
\end{tabular}

\section{Summing Scores}

Therapists should use T.T.E.S.S.K. at least two times during the TT treatment. The first time must necessarily be after the decision to start a TT treatment. The second, however, should be after the last Tecar session. In this way the therapist can obtain an overview of the treatment, but also of the patient's tissue, psychological and muscular response. It is highly recommended to continue the follow-up of the patient, using T.T.E.S.S.K. even fifteen days after the end of the treatment, to evaluate any postural imbalances, discharges during the walking process, or other musculotendinous problems. We attach physiological and non-physiological summing scores, in order to give the therapist a guideline to follow, after evaluating the patient with our system.

Physiological patient, no swelling, physiological ROM and \%MVIC, no pain, no TrPs lines:

157 (CRSS: 77; ROM: 16; \%MVIC: 48; NRS: 8; TrPs: 8)

Non-physiological patient, mild swelling, ROM and $\%$ MVIC in normal ranges, mild pain, few TrPs:

87 (CRSS:47; ROM: 10; \%MVIC: 24; NRS:3; TrPs:3)

Non-physiological patient, severe swelling, poor ROM and \%MVIC, severe pain, several TrPs:

14 (CRSS:7; ROM: 0; \%MVIC: 6; NRS:1; TrPs:0)

\section{Final Considerations}

This review aimed at building up a system that is able to work side by side with therapists. T.T.E.S.S.K. is a new Scale that wants to help clinicians keeping track of elaborate scores. It is important not to waste therapist's time during the treatment, as TTESSK is a system that allows to act even during specific phases of a sports injury. In fact, Tecar Treatment is often localized during acute phases of an inflammatory process or a tissue injury. As we have said previously, Tecar Therapy is a method of tissue care that is still poorly understood. We hope that with this article it will be possible to positively influence the medical-scientific community to approve the benefits of the treatment and to start a more global phase of experimentation on the physiological effects of this electro-medical machine. 
${ }^{1}$ Does the Application of Tecar Therapy Affect Temperature and Perfusion of Skin and Muscle Microcirculation? A Pilot Feasibility Study on Healthy Subjects

Ron Clijsen, Diego Leoni, Alessandro

Schneebeli, Corrado Cescon, Emiliano Soldini, Lihui

Li, Marco Barbero

$J$ Altern Complement Med

. 2020 Feb;26(2):147-153.

doi: 10.1089/acm.2019.0165. Epub 2019 Oct 3.

${ }^{2}$ Effectiveness of thermal and a thermal short-wave diathermy for the management of knee osteoarthritis: a systematic review and meta-analysis

$Y$ Laufer, G Dar

2012 Sep;20(9):957-66.

doi: 10.1016/j.joca.2012.05.005. Еpub 2012 May 30.

${ }^{3}$ [Tecar therapy]

Iaira Boissevain

2014 Apr 1;139(4):15.

${ }^{4}$ [TECAR therapy for Peyronie's disease: a phaseone prospective study. Great evidence in patients with erectile dysfunction]

Carlo Pavone, Davide Castrianni, Salvatore

Romeo, Enrica Napoli, Manuela Usala, Giuseppa

Gambino, Dalila Scaturro, Giulia Letizia Mauro

Apr-Jun 2013;80(2):148-53.

doi: 10.5301/RU.2013.10756

${ }^{5}$ Effects of a capacitive-resistive electric transfer therapy on physiological and biomechanical parameters in recreational runners: A randomized controlled crossover trial

Iratxe Duñabeitia, Haritz Arrieta, Jon Torres-

Unda, Javier Gil, Jordan Santos-Concejero, Susana $M$ Gil, Jon Irazusta, Iraia Bidaurrazaga-Letona $2018 \mathrm{Jul} ; 32: 227-234$.

doi: 10.1016/j.ptsp.2018.05.020. Epub 2018 May 26.

${ }^{6}$ Deep heating therapy via microwave diathermy relieves pain and improves physical function in patients with knee osteoarthritis: a double-blind randomized clinical trial

A Rabini, D B Piazzini, G Tancredi, C Foti, G

Milano, G Ronconi, A Specchia, P E Ferrara, $L$

Maggi, E Amabile, M Galli, R Bernabei, C Bertolini, E

Marzetti

2012 Dec;48(4):549-59.

Epub 2012 Jul 23.
${ }^{7}$ Range of motion measurements: reference values and a database for comparison studies

$J$ M Soucie, C Wang, A Forsyth, S Funk, M Denny, $K$ E Roach, D Boone, Hemophilia Treatment Center

Network

2011 May;17(3):500-7.

doi: 10.1111/j.1365-2516.2010.02399.x. Еpub 2010

Nov 11.

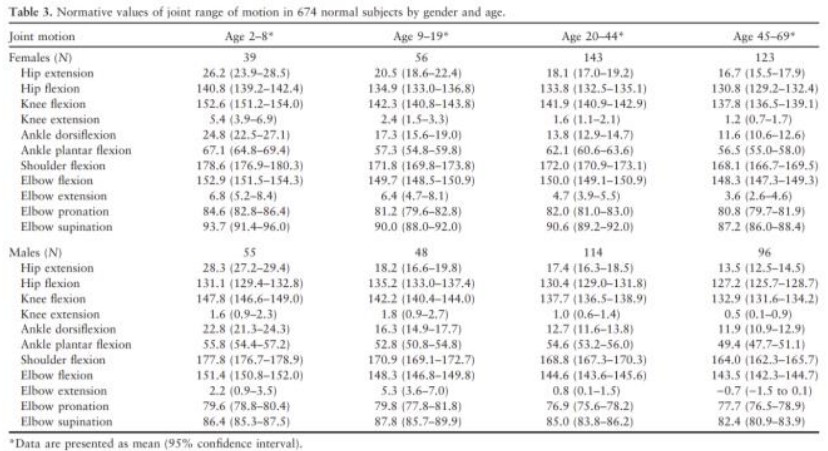

Haemophilia (2011), 17, 500-50

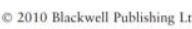

${ }^{8}$ Evaluation of knee range of motion: Correlation between measurements using a universal goniometer and a smartphone goniometric application

Rafael Aparecido Dos Santos, Viviane

Derhon, Michelle Brandalize, Danielle

Brandalize, Luciano Pavan Rossi

$2017 \mathrm{Jul} ; 21(3): 699-703$

doi: 10.1016/j.jbmt.2016.11.008. Epub 2016 Nov 17.

\author{
${ }^{9}$ Ankle-dorsiflexion range of motion and landing \\ biomechanics \\ Chun-Man Fong, J Troy Blackburn, Marc F \\ Norcross, Melanie McGrath, Darin A Padua \\ Jan-Feb 2011;46(1):5-10. \\ doi: 10.4085/1062-6050-46.1.5
}

${ }^{10}$ Altered knee and ankle kinematics during squatting in those with limited weight-bearing-lunge ankledorsiflexion range of motion

Karli E Dill, Rebecca L Begalle, Barnett S

Frank, Steven M Zinder, Darin A Padua

Nov-Dec 2014;49(6):723-32.

doi: 10.4085/1062-6050-49.3.29.

${ }^{11}$ Maximum voluntary isometric contraction (MVIC)

Merit Cudkowicz, Hui Zhang, Muhammad

Qureshi, David Schoenfeld

2004 Sep;5 Suppl 1:84-5.

doi: 10.1080/17434470410019744. 


\section{${ }^{12}$ Differences in Maximum Voluntary Excitation} Between Isometric and Dynamic Contractions are Age-Dependent

Remco J Baggen, Jaap H van Dieën, Sabine M Verschueren, Evelien Van Roie, Christophe Delecluse 2019 Jun 1;35(3):196-201.

doi: 10.1123/jab.2018-0215. Epub 2019 May 5.

\section{${ }^{13}$ Standards for quantification of EMG and neurography}

Erik Stålberg, Hans van Dijk, Björn Falck, Jun

Kimura, Christoph Neuwirth, Matthew Pitt, Simon

Podnar, Devon I Rubin, Seward Rutkove, Donald B

Sanders, Masahiro Sonoo, Hatice Tankisi, Machiel

Zwarts

2019 Sep;130(9):1688-1729.

doi: 10.1016/j.clinph.2019.05.008. Eрub 2019 Jun 10.

${ }^{14}$ Maximum voluntary isometric contraction: reference values and clinical application

Dara Meldrum, Eibhlis Cahalane, Ronan Conroy, Deirdre Fitzgerald, Orla Hardiman 2007 Feb;8(1):47-55.

doi: 10.1080/17482960601012491.
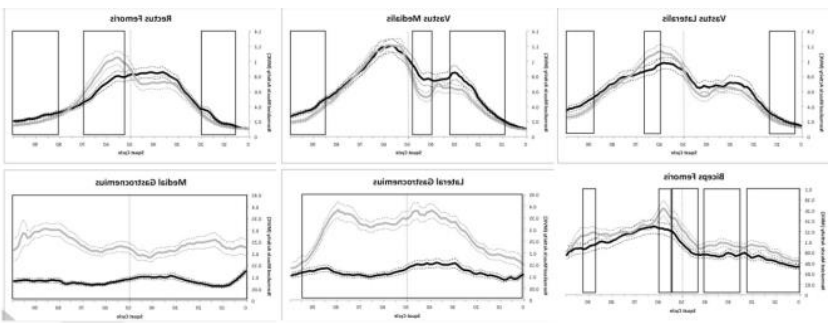

${ }^{15}$ Muscle Activation in Unilateral Barbell Exercises: Implications for Strength Training and Rehabilitation Lasse Mausehund, Audun E Skard, Tron Krosshaug 2019 Jul;33 Suppl 1:S85-S94. doi: 10.1519/JSC.0000000000002617.

${ }^{16}$ Quadriceps femoris muscle weakness and activation failure in patients with symptomatic knee osteoarthritis

Michael D Lewek, Katherine S Rudolph, Lynn Snyder-

Mackler

2004 Jan;22(1):110-5.

doi: 10.1016/S0736-0266(03)00154-2.

\footnotetext{
${ }^{17}$ Muscle Activation Patterns During Different Squat Techniques

Lindsay V Slater, Joseph M Hart

2017 Mar;31(3):667-676.

doi: 10.1519/JSC.0000000000001323.
}

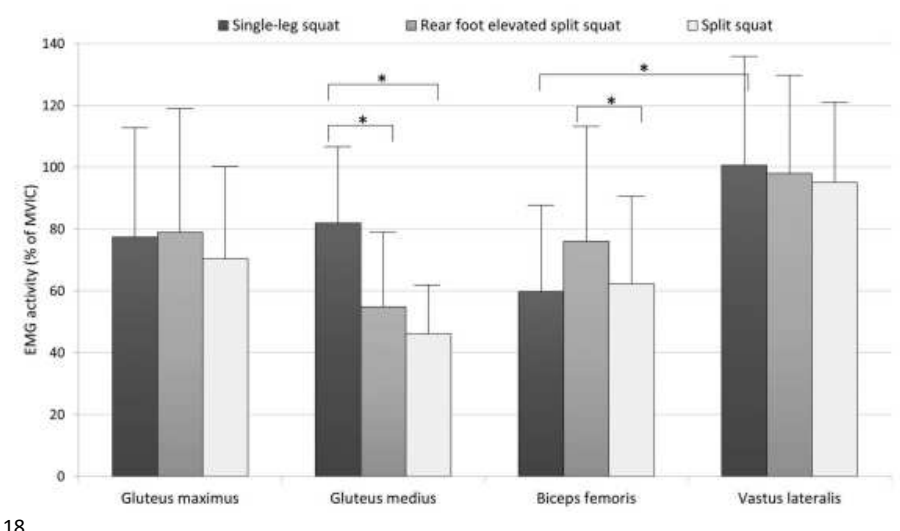

18

http://www.orthopaedicscore.com/scorepages/cincinna ti.html

\author{
${ }^{19}$ Wound repair and regeneration \\ $J$ M Reinke , H Sorg \\ 2012;49(1):35-43. \\ doi: 10.1159/000339613. Epub 2012 Jul 11.
}

${ }^{20} \mathrm{~A}$ rationale for assessing sports activity levels and limitations in knee disorders

$F R$ Noyes, $S$ D Barber, L A Mooar

1989 Sep;(246):238-49.

${ }^{21}$ Pain: a review of three commonly used pain rating scales

Amelia Williamson, Barbara Hoggart

2005 Aug;14(7):798-804.

doi: 10.1111/j.1365-2702.2005.01121.x.

\section{${ }^{22}$ Studies comparing Numerical Rating Scales,}

Verbal Rating Scales, and Visual Analogue Scales for assessment of pain intensity in adults: a systematic literature review

Marianne Jensen Hjermstad, Peter M Fayers, Dagny F Haugen, Augusto Caraceni, Geoffrey W Hanks, Jon H Loge, Robin Fainsinger, Nina Aass, Stein Kaasa, European Palliative Care Research Collaborative (EPCRC) 2011 Jun;41(6): 1073-93. doi: 10.1016/j.jpainsymman.2010.08.016

${ }^{23} A$ systematic review of the pain scales in adults: Which to use?

Ozgur Karcioglu, Hakan Topacoglu, Ozgur

Dikme, Ozlem Dikme

2018 Apr;36(4):707-714.

doi: 10.1016/j.ajem.2018.01.008. Epub 2018 Jan 6. 
${ }^{24}$ Anterior knee pain: an update of physical therapy Suzanne Werner 2014 Oct;22(10):2286-94.

doi: 10.1007/s00167-014-3150-y. Epub 2014 Jul 6.

${ }^{25}$ An efficient framework for estimation of muscle fiber orientation using ultrasonography Shan Ling, Bin Chen, Yongjin Zhou, Wan-Zhang Yang, Yu-Qian Zhao, Lei Wang, Yong-Ping Zheng 2013 Sep 30;12:98.

doi: $10.1186 / 1475-925 X-12-98$.

${ }^{26}$ Variability in human quadriceps muscles: quantitative study and review of clinical literature P L T Willan, J A Ransome, M Mahon 2002 Mar;15(2):116-28. doi: 10.1002/ca.1106.

${ }^{27}$ NIH Image to ImageJ: 25 years of image analysis Caroline A Schneider, Wayne S Rasband, Kevin W Eliceiri

$2012 \mathrm{Jul} ; 9(7): 671-5$.

doi: 10.1038/nmeth.2089.

${ }^{28}$ Myofascial Trigger Point Pain Syndromes

Robert D Gerwin

2016 Oct;36(5):469-473.

doi: 10.1055/s-0036-1586262. Epub 2016 Sep 23.

${ }^{29}$ Myofascial Trigger Points Then and Now: A Historical and Scientific Perspective

Jay P Shah, Nikki Thaker, Juliana Heimur, Jacqueline $V$ Aredo, Siddhartha Sikdar, Lynn Gerber

$2015 \mathrm{Jul} ; 7(7): 746-761$.

doi: 10.1016/j.pmrj.2015.01.024. Epub 2015 Feb 24.
${ }^{30}$ Responsiveness of Myofascial Trigger Points to Single and Multiple Trigger Point Release Massages: A Randomized, Placebo Controlled Trial

Albert F Moraska, Sarah J Schmiege, John D Mann, Nathan Butryn, Jason P Krutsch 2017 Sep;96(9):639-645.

doi: 10.1097/PHM.0000000000000728.

\begin{tabular}{lcccc} 
Muscle & $\begin{array}{c}\text { Assessed at } \\
\text { Baseline }\end{array}$ & $\begin{array}{c}\text { Identified } \\
\text { as Active }\end{array}$ & $\begin{array}{c}\text { Identified } \\
\text { as Latent }\end{array}$ & $\begin{array}{c}\text { Latent } \\
\text { MTrP }\end{array}$ \\
\hline $\begin{array}{c}\text { Suboccipital- } \\
\text { right (all) }\end{array}$ & 62 & $64.5 \%$ & $25.8 \%$ & $90.3 \%$ \\
Massage & 20 & $70.0 \%$ & $25.0 \%$ & $95.0 \%$ \\
Placebo & 21 & $57.1 \%$ & $33.3 \%$ & $90.5 \%$ \\
Wait-list & 21 & $66.7 \%$ & $19.0 \%$ & $85.7 \%$ \\
Suboccipital- & 62 & $61.3 \%$ & $27.4 \%$ & $88.7 \%$ \\
left (all) & & & & \\
Massage & 20 & $70.0 \%$ & $25.0 \%$ & $90.0 \%$ \\
Placebo & 21 & $47.6 \%$ & $42.9 \%$ & $95.5 \%$ \\
Wait-list & 21 & $66.7 \%$ & $14.3 \%$ & $80.9 \%$ \\
UT-right (all) & 61 & $50.8 \%$ & $41.0 \%$ & $91.8 \%$ \\
Massage & 19 & $42.1 \%$ & $47.4 \%$ & $89.5 \%$ \\
Placebo & 21 & $61.9 \%$ & $28.6 \%$ & $90.5 \%$ \\
Wait-list & 21 & $47.6 \%$ & $47.6 \%$ & $95.2 \%$ \\
UT-left (all) & 62 & $54.8 \%$ & $33.9 \%$ & $88.7 \%$ \\
Massage & 20 & $65.0 \%$ & $25.0 \%$ & $90.0 \%$ \\
Placebo & 21 & $47.6 \%$ & $42.9 \%$ & $90.9 \%$ \\
Wait-list & 21 & $52.4 \%$ & $33.3 \%$ & $85.7 \%$ \\
\hline
\end{tabular}

${ }^{31}$ Effects of Trigger Point Dry Needling for the Management of Knee Pain Syndromes: A Systematic Review and Meta-Analysis

Youssef Rahou-El-Bachiri, Marcos J NavarroSantana, Guido F Gómez-Chiguano, Joshua A Cleland, Ibai López-de-Uralde-Villanueva, César Fernández-de-Las-Peñas, Ricardo Ortega-

Santiago, Gustavo Plaza-Manzano 2020 Jun 29;9(7):2044. doi: 10.3390/jcm9072044. 